\title{
Use of the Dual Stator Induction Machine in Photovoltaic - Wind Hybrid Pumping
}

\author{
Arezki Adjati*, Toufik Rekioua, Djamila Rekioua \\ Laboratoire de Technologie Industrielle et de l'Information, Faculté de Technologie, Université de Bejaia, Bejaia 06000, \\ Algeria
}

Corresponding Author Email: adjati@ hotmail.fr

https://doi.org/10.18280/jesa.540113

Received: 17 August 2020

Accepted: 20 December 2020

\section{Keywords:}

centrifugal pump, dual stator induction motor (DSIM), dual stator induction generator (DSIG), hybrid pumping system (HPS), photovoltaic generator $(G P V)$, renewable energy, wind turbine

\begin{abstract}
In this article, a combination of two renewable sources is used to power a pumping station. Indeed, a photovoltaic generator (GPV) and a wind turbine are installed so as to be complementary in the process of filling the water tower similar to an accumulator, before distributing the water by gravity. Prior knowledge of a few quantities, in particular the assessment of water requirements, total dynamic head (TDH) and flow rate is essential for sizing the various components of the pumping chain. The results obtained show that the combination of the energy of the sun with that of the wind ensures a continuity of service; the use of an engine (DSIM) and a double stator induction generator (DSIG) allows degraded mode operation in the event that one or more parts of the drive system are defective. The global system is dimensioned and simulated under Matlab/ Simulink Package.
\end{abstract}

\section{INTRODUCTION}

In full swing, the real bet of the industrialized countries is, without doubt, the search for new sources of energy, preferably renewable, in substitution for the usual so-called conventional sources. A combination of the two available and inexhaustible energies, including the energy of the sun and that of the wind, will be an excellent alternative to electrify isolated sites not connected to electrical networks and supply pumping stations to draw water [1].

Semmache et al. [2] had opted for a combination of solar and conventional energy in order to reduce the consumption bill and preserve the environment by using so-called green energies. To obtain better control and better optimization between the different functions of the elements of a photovoltaic pumping system Mayssa and Sbita [3] have inserted an intelligent control method to provide the maximum power point with an improvement in system performance by obtaining a pumping flow of up to three times more.

Khan et al. [4] found that irrigation with solar power of certain crops like potato, cotton, soy, sunflower, strawberry, lentil, mustard are very much lucrative compared to diesel powered irrigation.

Hajdidj et al. [5] had introduced a battery storage system to the PV-wind hybrid system and had identified the main obstacle to energy production for hybrid systems, which is only the failure of one of the sources.

For our part, we opted for a double stator induction motor (DSIM) to drive the centrifugal pump and we used the double stator induction generator (DSIG) for the wind turbine. The reason for this convincing choice is undoubtedly the increased reliability and robustness of the double star induction machine that can still rotate even in the event of loss of supply phases or short circuit in the stator windings and provide the torque necessary to pump water under degraded conditions [6].

Besides to the fact that hybrid pumping makes it possible to obtain clearly significant flow rates, our proposal to combine these two renewable energies is justified by the fact that photovoltaic (PV) and wind turbine are not in competition, but on the contrary, they can strengthen mutually, while saving the additional cost of batteries which are simply replaced by a large capacity water tower.

\section{COMPONENTS OF HYBRID PUMPING SYSTEM}

As shown in Figure 1, this system consists of a photovoltaic source and a wind turbine equipped with a DSIG, an AC/DC converter, two DC/DC converters, two DC/AC inverters which supply the DSIM which drives a centrifugal pump which draws water from a borehole towards a water tower in order to distribute it by gravity $[6,7]$.

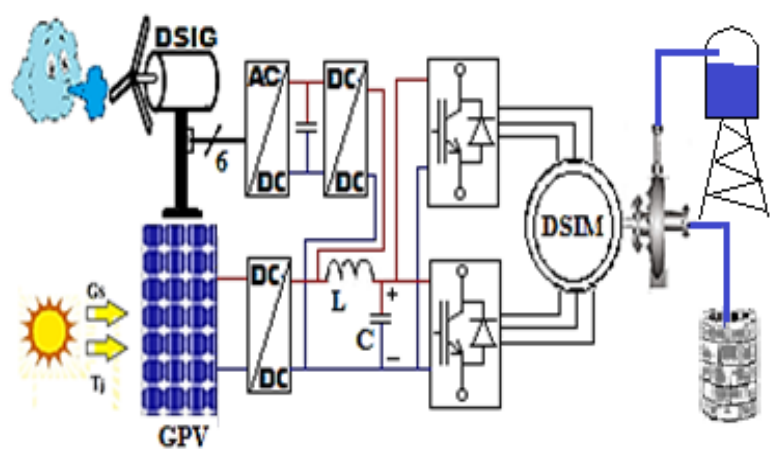

Figure 1. Hybrid photovoltaic-wind turbine installation

\subsection{DSIM model}

The power segmentation of multiphase machines is obtained when the number of phases of the stator increases, which leads to a decrease in the current per phase without the 
voltage per phase being increased. The total power is thus distributed over the different phases [8].

The electrical equations of the DSIM are given as [8]:

$$
\begin{aligned}
& {\left[\begin{array}{l}
v_{a 1} \\
v_{b 1} \\
v_{c 1}
\end{array}\right]=\left[\begin{array}{ccc}
R_{s} & 0 & 0 \\
0 & R_{s} & 0 \\
0 & 0 & R_{s}
\end{array}\right]\left[\begin{array}{l}
i_{a 1} \\
i_{b 1} \\
i_{c 1}
\end{array}\right]+\frac{d}{d t}\left[\begin{array}{l}
\varphi_{a 1} \\
\varphi_{b 1} \\
\varphi_{c 1}
\end{array}\right]} \\
& {\left[\begin{array}{l}
v_{a 2} \\
v_{b 2} \\
v_{c 2}
\end{array}\right]=\left[\begin{array}{ccc}
R_{s} & 0 & 0 \\
0 & R_{s} & 0 \\
0 & 0 & R_{s}
\end{array}\right]\left[\begin{array}{l}
i_{a 2} \\
i_{b 2} \\
i_{c 2}
\end{array}\right]+\frac{d}{d t}\left[\begin{array}{l}
\varphi_{a 2} \\
\varphi_{b 2} \\
\varphi_{c 2}
\end{array}\right]} \\
& {\left[\begin{array}{l}
0 \\
0 \\
0
\end{array}\right]=\left[\begin{array}{ccc}
R_{r} & 0 & 0 \\
0 & R_{r} & 0 \\
0 & 0 & R_{r}
\end{array}\right]\left[\begin{array}{l}
I_{a r} \\
I_{b r} \\
I_{c r}
\end{array}\right]+\frac{d}{d t}\left[\begin{array}{l}
\varphi_{a r} \\
\varphi_{b r} \\
\varphi_{c r}
\end{array}\right]}
\end{aligned}
$$

The magnetic equations are:

$$
\left[\begin{array}{l}
\varphi_{1, a b c} \\
\varphi_{2, a b c} \\
\varphi_{r, a b c}
\end{array}\right]=\left[\begin{array}{lll}
L_{s 1, s 1} & L_{s 1, s 2} & L_{s 1, r} \\
L_{s 2, s 1} & L_{s 2, s 2} & L_{s 2, r} \\
L_{r, s 1} & L_{r, s 2} & L_{r, r}
\end{array}\right]\left[\begin{array}{l}
i_{1, a b c} \\
i_{2, a b c} \\
i_{r, a b c}
\end{array}\right]
$$

The magnetic energy is [9]:

$$
\omega_{\text {mag }}=\frac{1}{2}\left(\left[I_{s 1}\right]^{t}\left[\phi_{s 1}\right]+\left[I_{s 2}\right]^{t}\left[\phi_{s 2}\right]+\left[I_{r}\right]^{t}\left[\phi_{r}\right]\right)
$$

The electromagnetic torque is given by the derivative of magnetic energy versus mechanical angle $[8,9]$.

$$
T_{e m}=\frac{d \omega_{m a g}}{d \theta_{m}}=p \cdot \frac{d \omega_{m a g}}{d \theta_{e}}
$$

The basic mechanical equation that governs the movement of the rotor of the DSIM can be given by [6]:

$$
I . \frac{d \Omega}{d t}=T_{e m}-T_{r}-F_{r} \Omega
$$

Reliability is ensured by operation under degraded conditions and spatial harmonics of a certain order are eliminated. Torque ripples are damped faster in a multi-phase machine and the power factor is improved compared to the three-phase asynchronous machine [10].

The use of a voltage inverter unfortunately causes current harmonics of large amplitude and the fact that the number of phases is large, the number of semiconductors used also increases, which generates an additional cost of the installation $[10,11]$.

\subsection{GPV modeling}

The explicit Rauschenbach model offers equations which allow the characteristic curve of a solar cell to be generated by knowing the open circuit voltage "Voc", the maximum power voltage "Vm", the short-circuit current "Icc" and the current at maximum power "Im" [12].

Figure 2 represents the GPV which generates the following current:

$$
I=I_{c c} \times\left[1-C_{1} \times\left[\exp \left(\frac{V}{V_{o c} \times C_{2}}-1\right)\right]\right]
$$

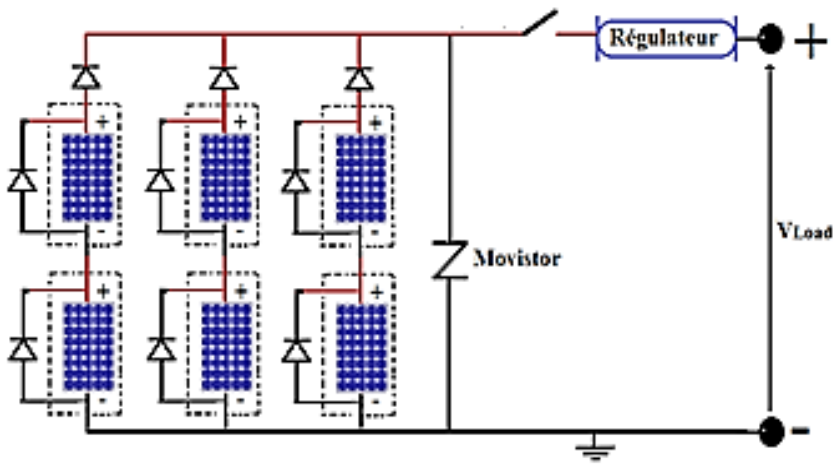

Figure 2. Diagram of photovoltaic generator

The constants $\mathrm{C} 1$ and $\mathrm{C} 2$ are defined by:

$$
\begin{gathered}
C_{1}=\left(1-\frac{I_{m}}{I_{c c}}\right) \times \exp \left(\frac{-V_{m}}{V_{o c} \times C_{2}}\right) \\
C_{2}=\left(\frac{V_{m}}{V_{o c}}-1\right) / \ln \left(1-\frac{I_{m}}{I_{c c}}\right)
\end{gathered}
$$

The voltage "Vm" corresponding to the maximum power is calculated by the equation [13]:

$$
V_{m}=V_{\text {mref }}\left[1+\Delta V_{m}\left(T_{j}-T_{\text {jref }}\right)\right]+K_{1} V_{T} \ln \left(\frac{G_{s}}{G_{\text {sref }}}\right)+K_{2} V_{T} \ln ^{2}\left(\frac{G_{s}}{G_{\text {sref }}}\right)
$$

The current "Im" corresponding to the maximum power is obtained by [13]:

$$
I_{m}=I_{m r e f} \times\left(\frac{G_{s}}{G_{\text {sref }}}\right) \times\left[1+\Delta I_{m} \times\left(T_{j}-T_{\text {jref }}\right)\right]
$$

where, Vmref, Imref: Voltage \& current at maximum power point in standard condition, $\Delta \mathrm{Vm}, \Delta \mathrm{Im}$ : Temperature coefficient of voltage and current at the point of maximum power and $\alpha, \beta$ : Constant parameters.

For the levels of sunshine $\mathrm{G}_{\mathrm{s}}\left[\mathrm{W} / \mathrm{m}^{2}\right]$ and temperature $\mathrm{T}\left[{ }^{\circ} \mathrm{C}\right]$, it is possible to use some equations in order to obtain new points from the reference points of sunshine and of the temperature [14].

$$
\left\{\begin{array}{c}
\Delta I=\alpha \times\left(\frac{G_{s}}{G_{s r e f}}\right) \times \Delta T+\left(\frac{G_{s}}{G_{s r e f}}-1\right) \times I_{c c} \\
\Delta V=-\beta \times \Delta T-R_{s} \times \Delta I
\end{array}\right.
$$

And the new values of current and voltage are:

$$
\left\{\begin{array}{c}
I_{\text {new }}=I_{\text {ref }}+\Delta I \\
V_{\text {new }}=V_{\text {ref }}-\Delta V
\end{array}\right.
$$

\subsection{Turbine modeling}

For deep wells with high flow rates, electric wind pumping is most suitable for isolated and fairly windy sites, with a competitive advantage compared to other energy sources. These isolated wind turbines are mainly used to supply residential areas or isolated telecommunication systems [15].

The electric system of a fixed-speed wind turbine is simpler and less expensive compared to variable-speed operation that 
offers increased energy efficiency and reduced torque oscillations. The majority of wind power applications are at constant speed, which allows the reactive energy of the selfpriming capacitors to be controlled [15]

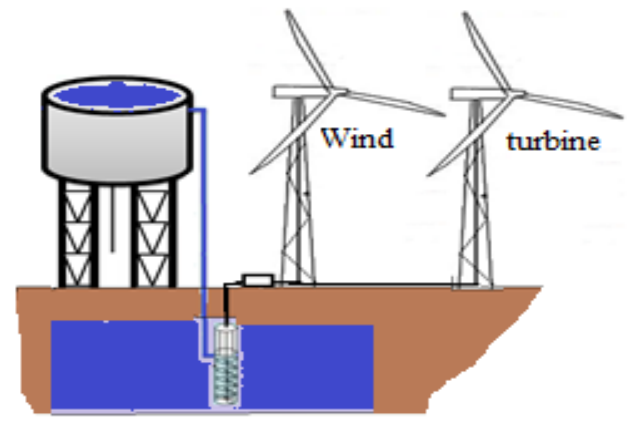

Figure 3. Electric pumping diagram

Figure 3 represent the electric pumping diagram and the aerodynamic power is given by:

$$
P_{e o l}=P_{T}=\frac{1}{2} \times \rho \times \pi \times R^{2} \times C_{p}(\lambda) \times V^{3}
$$

The turbine torque will therefore be:

$$
T_{T}=\frac{P_{T}}{\Omega_{T}}=\frac{1}{2} \times \rho \times \pi \times R^{3} \times C_{p}(\lambda) \times V^{2}
$$

where, $\rho$ : air density, R: blade length and V: wind speed.

For a small power wind turbine, the analytical equation of $\mathrm{Cp}$ as a function of $\lambda$ is given by [16]:

$$
\begin{aligned}
& C_{p}(\lambda)=7.9863 \times 10^{-5} \times \lambda^{5}-17.375 \times 10^{-4} \times \lambda^{4} \\
& -9.86 \times 10^{-3} \times \lambda^{3}-9.41 \times 10^{-3} \times \lambda^{2}+6.38 \times 10^{-2} \times \lambda+0.001
\end{aligned}
$$

\subsection{DSIG modeling}

The expression of the magnetization current is given as a function of the direct and quadrature magnetization currents by $[17,18]$ :

$$
\mid \begin{aligned}
& i_{m d}=-i_{d 1}-i_{d 2}+i_{d r} \\
& i_{m q}=-i_{q 1}-i_{q 2}+i_{q r}
\end{aligned} \rightarrow i_{m}=\sqrt{i_{m d}^{2}+i_{m q}^{2}}
$$

The DSIG is driven at a speed greater than that of synchronism and the self-priming of the generator is achieved through the addition of capacitors with precise values, added to this, the presence of a remanent field in the rotor iron [17].

The magnetizing inductance as a function of the magnetizing current "im" is given by $[19,20]$ :

$$
L_{m}=0.1406+0.0014 \times i_{m}-0.0012 \times i_{m}^{2}+5 \times 10^{-5} \times i_{m}^{3}
$$

The electromagnetic torque is given by:

$T_{e m}=\frac{3 \times p \times L_{m}}{2 \times\left(L_{r}+L_{m}\right)}\left[\varphi_{d r} \times\left(i_{q 1}+i_{q 2}\right)-\varphi_{q r} \times\left(i_{d 1}+i_{d 2}\right)\right]$

And the movement of the rotor can be governed by the following mechanical equation:

$$
T_{e m}=I \times \frac{d \Omega}{d t}+F_{r} \times \Omega+T_{r}
$$

The DSIG differential equation systems according to the "d, q" standard are given by the following electrical equations:

$$
\begin{gathered}
\left\{\begin{array}{c}
V_{d r}=r_{r} \times i_{d r}+p \times \varphi_{d r}-\left(\omega_{s}-\omega_{r}\right) \times \varphi_{q r}=0 \\
V_{q r}=r_{r} \times i_{q r}+p \times \varphi_{q r}+\left(\omega_{s}-\omega_{r}\right) \times \varphi_{d r}=0
\end{array}\right. \\
\left\{\begin{array}{c}
V_{d 1}=-r_{s} \times i_{d 1}+p \times \varphi_{d 1}-\omega_{s} \times \varphi_{q 1} \\
V_{q 1}=-r_{s} \times i_{q 1}+p \times \varphi_{q 1}+\omega_{s} \times \varphi_{d 1} \\
V_{d 2}=-r_{s} \times i_{d 2}+p \times \varphi_{d 2}-\omega_{s} \times \varphi_{q 2} \\
V_{q 2}=-r_{s} \times i_{q 2}+p \times \varphi_{q 2}+\omega_{s} \times \varphi_{d 2}
\end{array}\right.
\end{gathered}
$$

The rotor and stator flux according to the " $\mathrm{d}$, q" reference frame is given by [21]:

$$
\mid \begin{gathered}
\left\{\begin{array}{l}
\varphi_{d r}=L_{r} \times i_{d r}+L_{m d} \times i_{m d} \\
\varphi_{q r}=L_{r} \times i_{q r}+L_{m q} \times i_{m q}
\end{array}\right. \\
\left\{\begin{array}{l}
\varphi_{d 1}=-L_{s} \times i_{d 1}-L_{m} \times\left(i_{d 1}+i_{d 2}\right)-L_{d q} \times i_{q 2}+L_{m d} \times i_{m d} \\
\varphi_{q 1}=-L_{s} \times i_{q 1}-L_{m} \times\left(i_{q 1}+i_{q 2}\right)+L_{d q} \times i_{d 2}+L_{m q} \times i_{m q} \\
\varphi_{d 2}=-L_{s} \times i_{d 2}-L_{m} \times\left(i_{d 1}+i_{d 2}\right)+L_{d q} \times i_{q 1}+L_{m d} \times i_{m d} \\
\varphi_{q 2}=-L_{s} \times i_{q 2}-L_{m} \times\left(i_{q 1}+i_{q 2}\right)+L_{d q} \times i_{d 1}+L_{m q} \times i_{m q}
\end{array}\right.
\end{gathered}
$$

The necessary condition for self-priming is [22]:

$$
C \succ \frac{1}{L_{s} \times \omega_{s}^{2}}
$$

For a slip close to zero, the speed is very close to that of synchronism, which gives [22].

$$
C=\frac{1}{L_{s} \times \omega_{r o t}^{2}}
$$

In practice, only the value of Cmin is important and beyond Cmax, the operation becomes unstable.

\subsection{Centrifugal pump modeling}

The centrifugal pump is a flow generator that ensures the movement of a fluid from one point to another, when gravity does not perform this task.

In practice, hydraulic engineers "make their work easier", using simple formulas close to theory where, knowing the flow rate $\mathrm{Q}$ and $\mathrm{TDH}$, they can characterize the pumping system. With $\eta_{\text {tot }}=\eta_{\text {pump }} . \eta_{\text {engine. }} \eta_{\text {inverter }}$ and 0.367 as an unity corrector, the electrical power required is given by:

$$
P_{\text {delivred }}=\frac{Q \times T D H}{0.367 \times \eta_{t o t}}
$$

With, $\mathrm{K}_{\mathrm{r}}$ : Proportionality coefficient, $\omega_{\mathrm{r}}$ : rotation speed, the centrifugal pump opposes a resistant torque from which its expression is given by [6]: 


$$
T_{r}=K_{r} \omega_{r}^{2}+T_{s}
$$

To limit pressure drops and reduce energy costs, it is recommended not to exceed the water circulation speed in the piping of $0.5 \mathrm{~m} / \mathrm{s}$ and for this, larger diameter tubes are used.

The recommended diameter is:

$$
d=25 \times Q
$$

And the flow velocity is obtained by:

$$
v_{\text {flow }}=\frac{350 \times Q}{d^{2}}
$$

The pump can maintain excellent performance, providing a different flow rate and TDH, as long as the speed is changed.

The laws of similarity allow the deduction of the flow rate, the TDH and the power of the pump or of another pump in the case where the speed of the pump changes from a value N1 to a value N2 [11]:

The new flow, the new TDH and the new engine power are obtained by:

$$
\left\{\begin{array}{c}
Q_{2}=Q_{1} \times \frac{N_{2}}{N_{1}} \\
T D H_{2}=T D H_{1} \times\left(\frac{N_{2}}{N_{1}}\right)^{2} \\
P_{2}=P_{1} \times\left(\frac{N_{2}}{N_{1}}\right)^{3}
\end{array}\right.
$$

\section{SIZING OF A STAND-ALONE INSTALLATION}

For the supply of drinking water to a village located in a desert area not connected to the conventional electricity grid, the use of solar photovoltaic pumping and wind power is an attractive long-term solution.

Indeed, a water tower with a capacity of $150 \mathrm{~m}^{3}$, sufficient for the daily needs of the inhabitants, was erected in order to draw water from the only well in this area.

For nominal flow $\mathrm{Qn}=30 \mathrm{~m}^{3} / \mathrm{h}$, a $\mathrm{TDH}=17 \mathrm{~m}, \eta p u m p=0.55$, nengine $=0.85$, inverter $=0.9$, the recommended diameter of the pipes is:

$$
d=25 \times Q=25 \times 30=750 \mathrm{~mm}
$$

The pumping time is:

$$
T_{\text {pumping }}=\frac{V}{Q_{n}}=\frac{150}{30}=5 \text { hours }
$$

The total efficiency of the installation is:

$$
\eta_{\text {tot }}=\eta_{\text {pump }} \times \eta_{\text {engine }} \times \eta_{\text {inverter }}=0.55 \times 0.85 \times 0.95=0.444
$$

The electric power delivered is:

$$
P_{\text {delivred }}=\frac{Q \times T D H}{0.367 \times \eta_{\text {tot }}}=\frac{30 \times 17}{0.367 \times 0.444}=3130 \mathrm{~W}
$$

The daily energy required is:

$$
E_{c}=P_{\text {delivred }} \times T_{\text {pumping }}=3130 \times 5=15650 \mathrm{Wh} / \mathrm{d}
$$

The power losses attributable to temperature and dust represent one fifth of the power delivered by all the modules, the power of the GPV is:

$$
P_{g}=\frac{E_{c}}{T_{\text {pumping }} \times\left(1-\sum \text { losses }\right)}=\frac{15650}{5 \times(1-0.2)}=3912.5 \mathrm{~W}
$$

The model used is the SIEMENS SM 110-24 type panel, having a standardized nominal power of $110 \mathrm{Wp}$, the number of panels to be used is:

$$
N \geq \frac{P_{g}}{P_{\text {panel }}}=\frac{3912.5}{110}=35.55 \text { panels }
$$

The number of panels is, therefore, 36 panels.

To obtain the electrical energy equivalent to 36 photovoltaic panels, or $3960 \mathrm{~W}$, a three-bladed wind turbine operating at fixed speed is used in this region where the wind speed is average $6.5 \mathrm{~m} / \mathrm{s}$. The DSIG used for the conversion has an efficiency of 0.88 with a slip of $-1 \%$ and a speed multiplier having an efficiency of 0.9 . The mechanical power required to rotate the wind turbine blades is:

$$
P_{\text {Mec }}=\frac{P_{\text {elec }}}{\eta_{\text {Multi }} \times \eta_{D S I G}}=\frac{3960}{0.9 \times 0.88}=5000 \mathrm{~W}
$$

From the characteristic of the three blades wind turbine, the corresponding coefficients are $\mathrm{C}_{\mathrm{p}}=0.48$ and $\lambda=8$ [16].

From relation 12 , we obtain the length of the blades as follows:

$$
R=\left(\frac{2 \times P_{M e c}}{\rho \times \pi \times C_{p} \times V^{2}}\right)^{\frac{1}{3}}=\left(\frac{2 \times 5000}{1.22 \times \pi \times 0.48 \times 6.5^{2}}\right)^{\frac{1}{3}}=5.04 \simeq 5 \mathrm{~m}
$$

The speed of the blades being:

$$
N=\frac{30 \times \lambda \times V}{\pi \times R}=\frac{30 \times 8 \times 6.5}{\pi \times 5}=98.36 \mathrm{rpm}
$$

The multiplying coefficient is thus obtained by:

$$
K=\frac{N_{s}}{N}=\frac{1500}{98.36}=15.25
$$

So the wind turbine used has blades with a length of $5 \mathrm{~m}$, a speed multiplier with a ratio $\mathrm{K}=15.25$.

\section{RESULTS AND COMMENTS}

In the interval [0s-3s], the GPV supplies the DC bus to the two inverters used to supply the DSIM which will drive the centrifugal pump.

In the interval $[3 s-5 s]$, the necessary power is no longer guaranteed by the GPV, hence the need to resort to the wind generator by offering DC bus necessary after electrical rectification of the voltages generated by the DSIG with a wind made up of an oscillating component, varying around an average component of $6.5 \mathrm{~m} / \mathrm{s}$. 


\subsection{Pump simulation results}

At start-up, Figure 4 shows that the electromagnetic torque reaches a peak of $26 \mathrm{Nm}$ before reaching the resistive torque of the pump with an oscillating value of $\pm 2 \mathrm{Nm}$ around the torque of the pump which is $12 \mathrm{Nm}$.

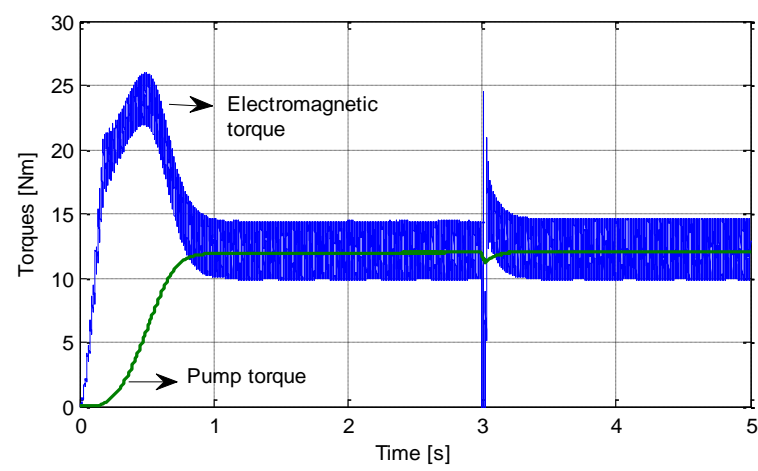

Figure 4. Electromagnetic \& pump torques

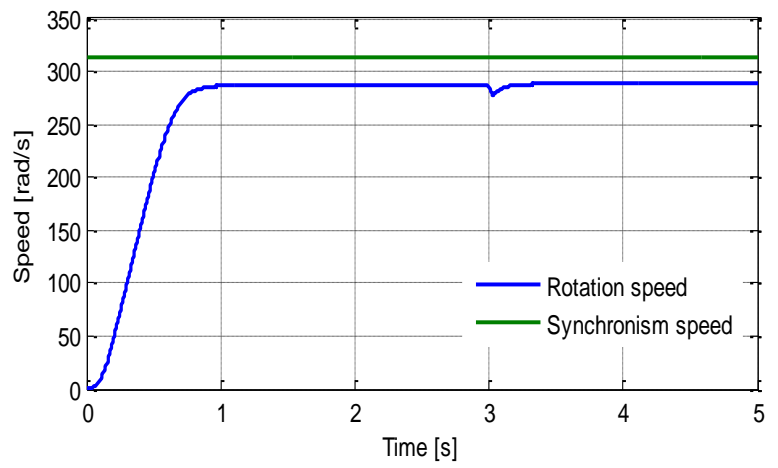

Figure 5. Rotative \& synchronism speed

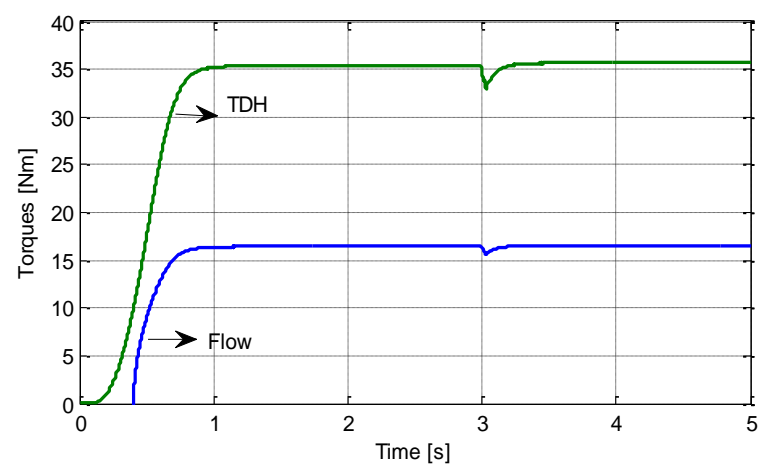

Figure 6. Characteristic flow - TDH

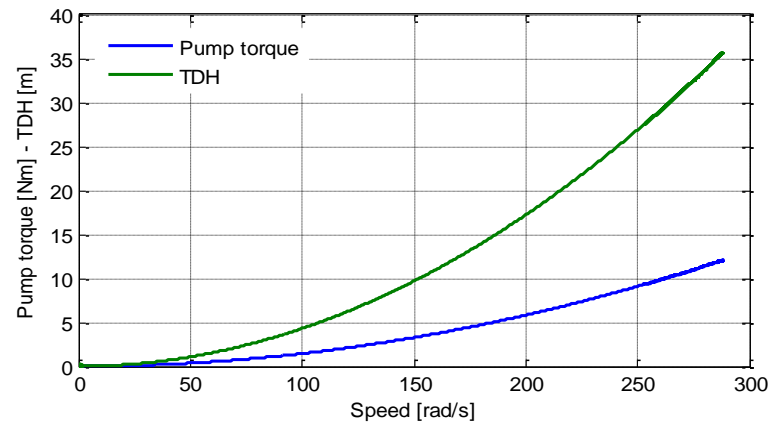

Figure 7. Characteristic Torque-speed \& TDH-speed

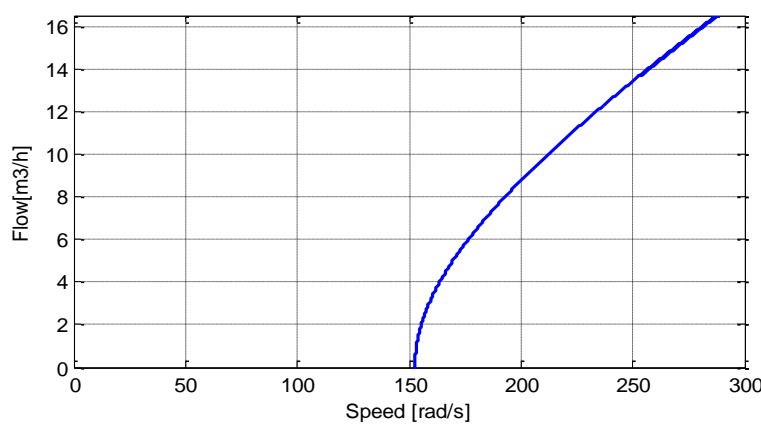

Figure 8. Characteristic flow - speed

Figure 5 and Figure 6 shows that the flow changes in the same way as the TDH and which is similar to the speed.

On the other hand, Figure 7 shows that the variation of the TDH is similar to that of the resistive torque which obeys, suitably, the variation as a function of the square of the speed of rotation in agreement with the relation 24 .

Figure 8 shows that before reaching a speed of $150 \mathrm{rad} / \mathrm{s}$, the pump piping does not provide any flow, then the flow increases with increasing rotational speed

\subsection{DSIG simulation results}

Thus, the DSIG is first tested at no-load and then tested with a resistive load to simulate rectification.

The value of the self-priming capacitors, represented by Figure 9, has an effect on the voltage supplied. We opted for $\mathrm{C}=40 \mu \mathrm{F}$

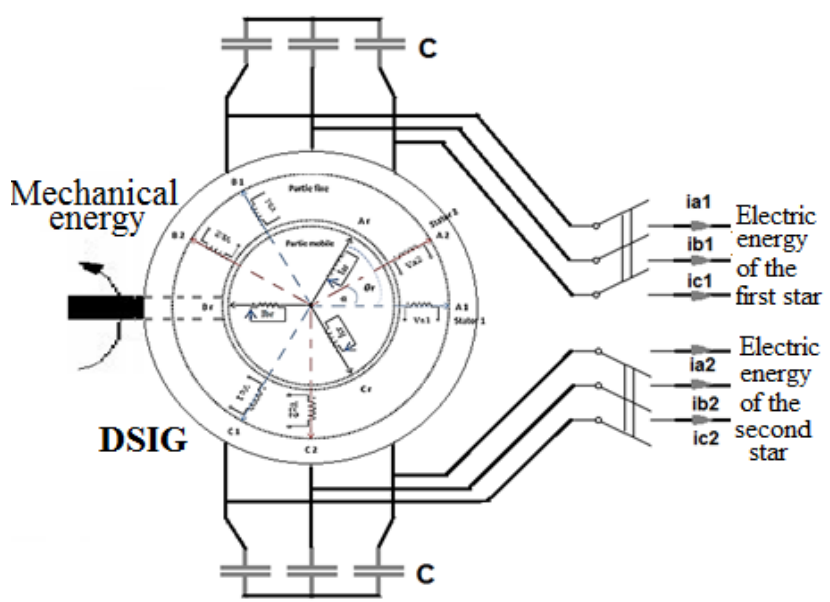

Figure 9. Diagram of a DSIG-based energy conversion

\subsubsection{Simulation of the no-load DSIG}

The rotor of the DSIG is driven at no load (without omitting the capacities) at a speed appreciably higher than the speed of synchronism.

Figures 10 and 11 shows, that in the presence of a remanent field, it is observed at the terminals of the two stars of the stator a voltage and a current which evolve exponentially before reaching a maximum voltage of $227.5 \mathrm{~V}$ and a current of 2.86 A.

At start-up, Figure 12 shows than the magnetizing inductance Lm takes a value of 0.14 Henry and increases slightly then decreases when the equilibrium state is established to stabilize at a value of $0.108 \mathrm{H}$, on the other hand than the magnetizing current increases from 0 to $7 \mathrm{~A}$. 

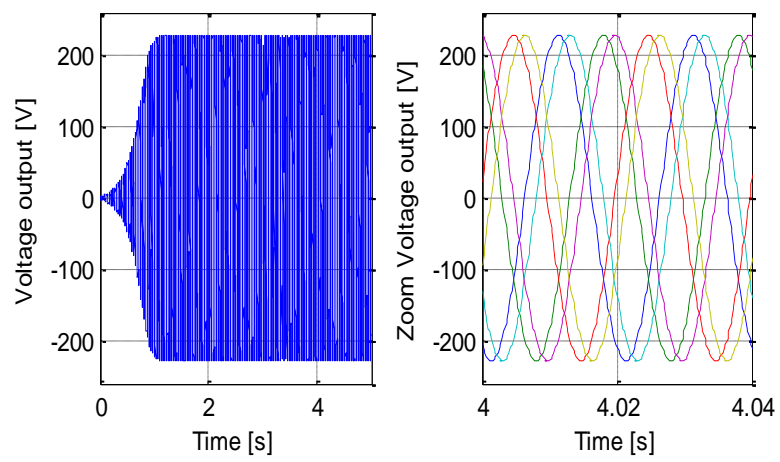

Figure 10. Voltages generated without load
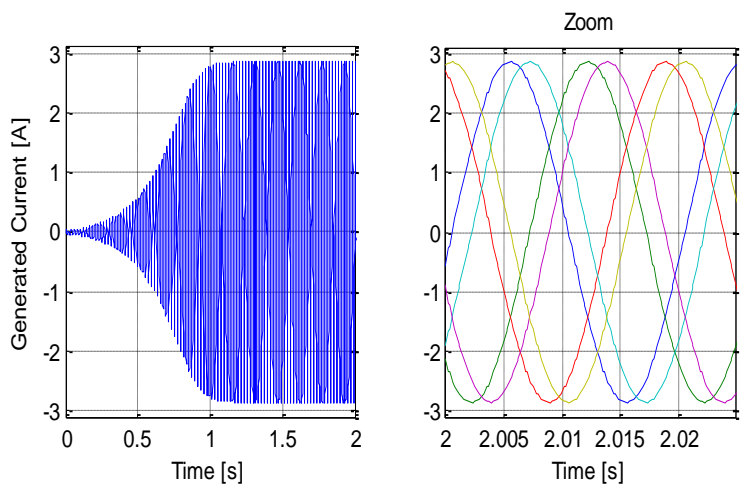

Figure 11. Current generated without load
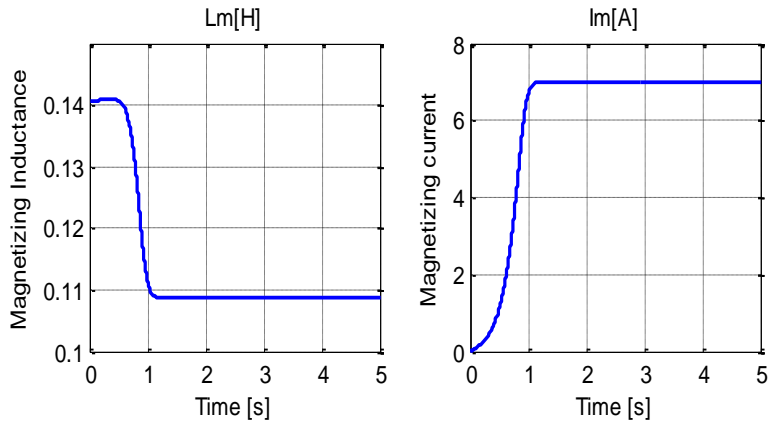

Figure 12. Magnetizing inductance \& current

Figure 13 reveals than the rotor current also increases and draws a sinusoidal shape with a maximum value of $0.14 \mathrm{~A}$ with a period $\mathrm{T}_{\text {rotor }}=12.46 \mathrm{~s}$ equivalent to a frequency mainly due to the slip of low value, approximately, close to zero, which reflects the no-load operation mode.

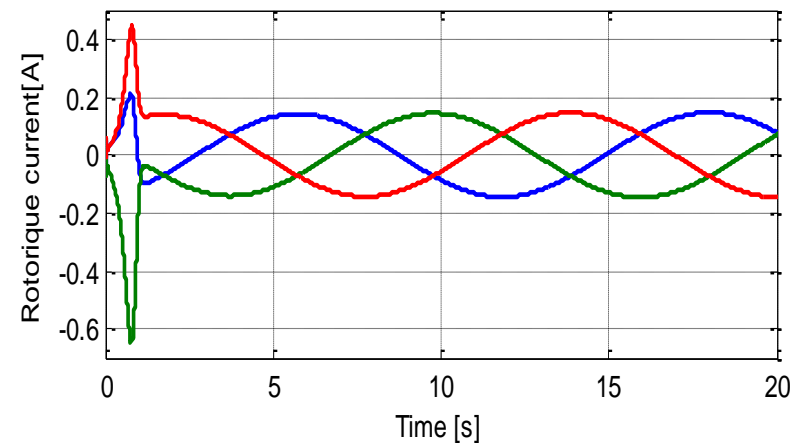

Figure 13. Rotorique current without load

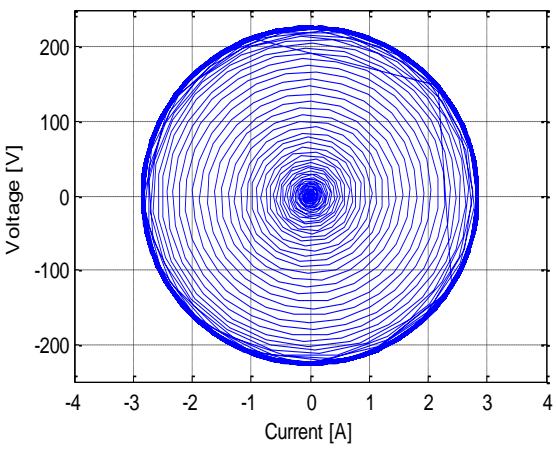

Figure 14. Lissajous curve

Figure 14 clearly shows the phase shift existing between the voltage and the current delivered at the terminals of the two stars of the stator. The circular Lissajous curve indicates that the phase shift is $90^{\circ}$, which confirms the operation without load but with the presence of the self-priming capacitors

\subsubsection{Simulation with a purely resistive load}

In this test, at $t=3 \mathrm{~s}$, a balanced resistive load of $200 \Omega$ is inserted at the generator output

Figure 15 reveals that the magnetizing inductance $\mathrm{Lm}$ increases from $0.108 \mathrm{H}$ to a fluctuating value between 0.126 $\mathrm{H}$ and $0.127 \mathrm{H}$ and that the magnetizing current decreases by $7 \mathrm{~A}$ to reach a floating value between $4.53 \mathrm{~A}$ and $4.72 \mathrm{~A}$.

When the load is connected, Figure 16 shows that the phaseto-neutral voltage across the two stars of the stator decreases to reach $168.4 \mathrm{~V}$ and Figure 17 shows the decrease in current from $2.86 \mathrm{~A}$ to $2.22 \mathrm{~A}$ and Figure 18 gives a current of $0.83 \mathrm{~A}$ which travels through the three resistances of the load.

The increase in the active power supplied by the generator is the cause of the increase in the currents induced in the rotor. Figure 19 shows the sinusoidal shape of the currents induced in the rotor having $2 \mathrm{~A}$ as maximum value and $1.4 \mathrm{~Hz}$ as frequency.
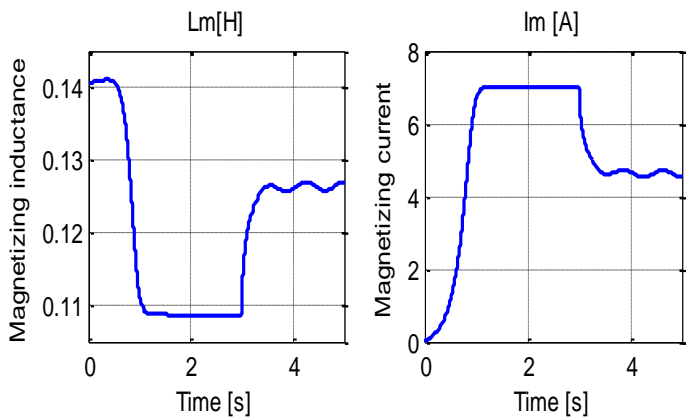

Figure 15. Magnetizing inductance \& current
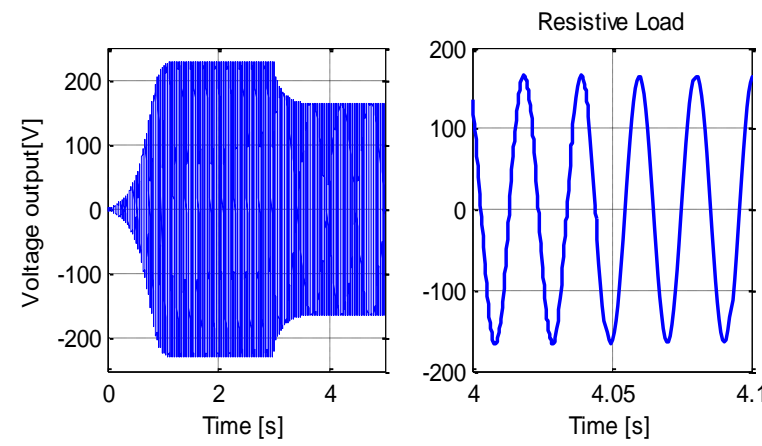

Figure 16. Voltages generated with resistive load 

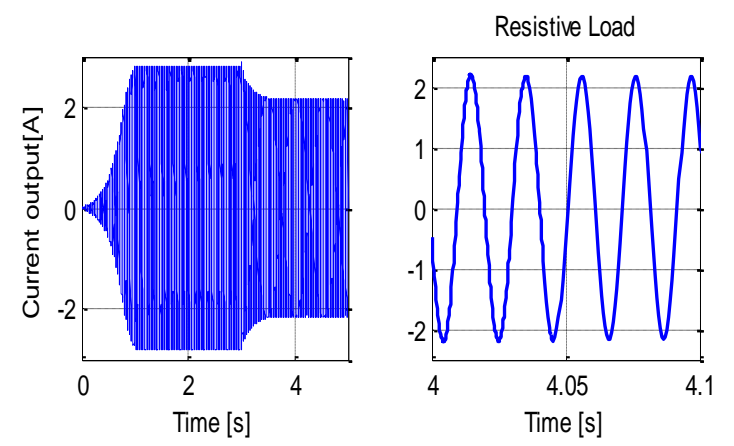

Figure 17. Current generated with resistive load
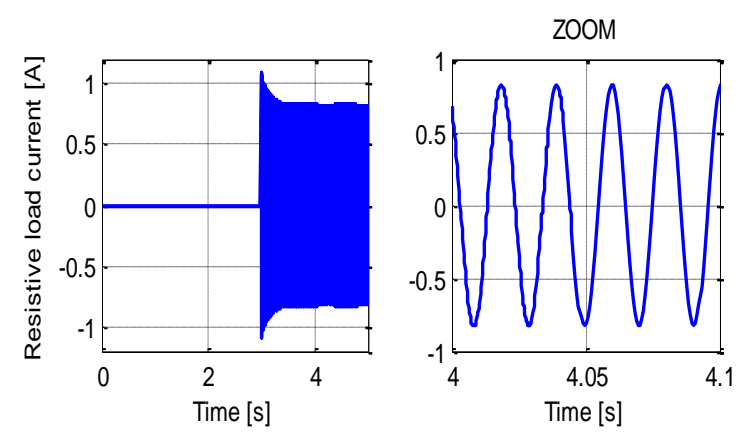

Figure 18. Resistive load current

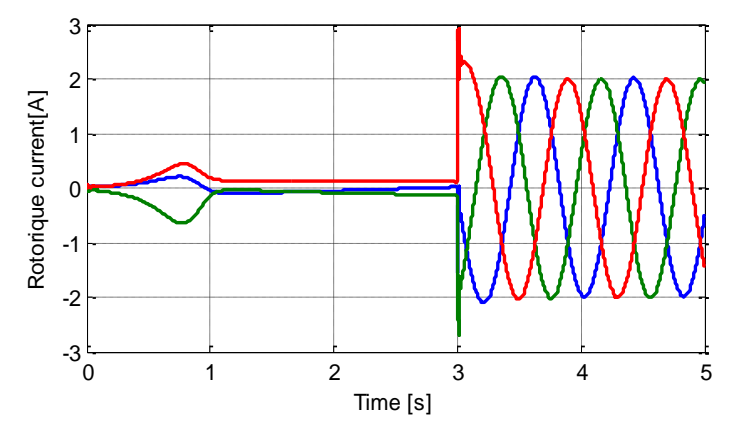

Figure 19. Rotorique current with resistive load

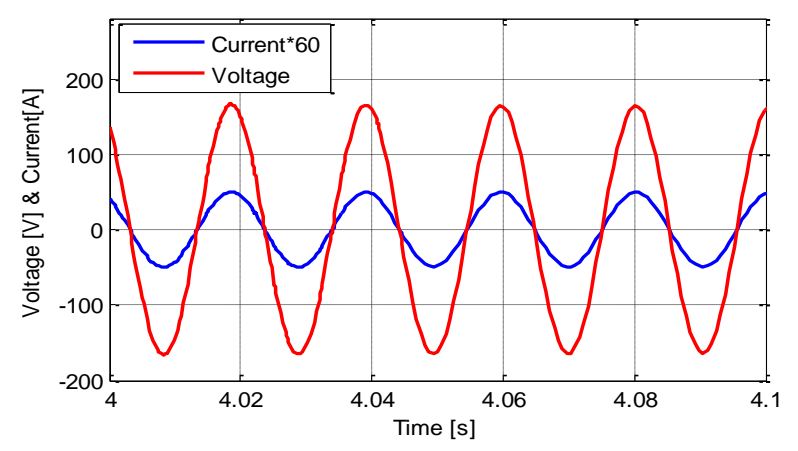

Figure 20. Voltage and current across the resistive load

Figure 20 indicates that the voltage and the current are in phase, that is to say a zero phase shift.

\subsubsection{Influence of the self-priming capacitor}

In order to establish the influence of the values of the selfstarting capacitors on the characteristics of the machine, we carried out simulations with capacities from $35 \mu \mathrm{F}$ to $55 \mu \mathrm{F}$ with a step of $5 \mu \mathrm{F}$.

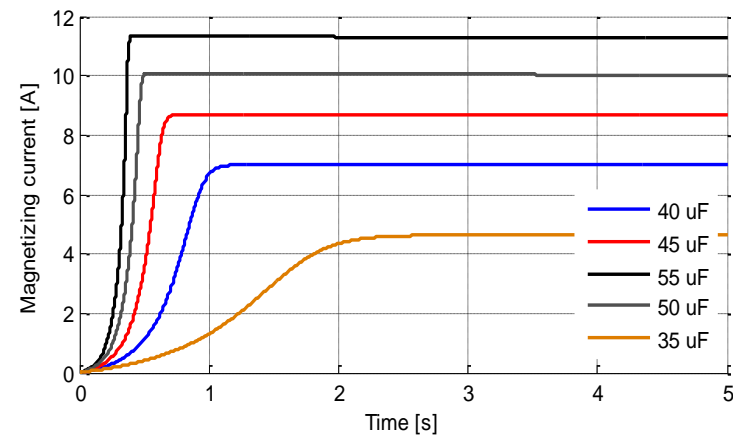

Figure 21. Influence of self-priming capacitors on the magnetizing current

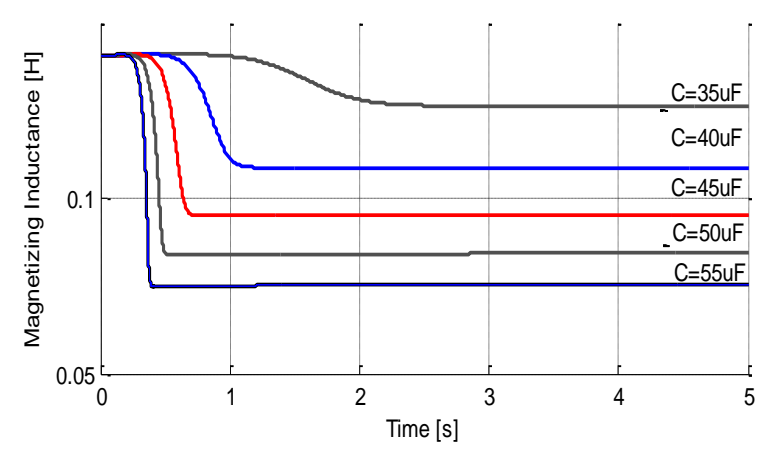

Figure 22. Influence of self-priming capacitors on magnetizing inductance

Figure 21 summarizes the various forms of the magnetizing current which increases from $4.63 \mathrm{~A}$ for $\mathrm{C}=35 \mu \mathrm{F}$ to $11.29 \mathrm{~A}$ for $\mathrm{C}=55 \mu \mathrm{F}$, contrary to what is shown in Figure 22 which shows that the value of the magnetizing inductance decreases as and as the value of $\mathrm{C}$ increases.

Table 1 shows that voltage, current and rotor current increase with the selection of a larger value of the self-priming capacitors. It is also interesting to add that the response time, decreases from $\mathrm{t}=2 \mathrm{~s}$ for $\mathrm{C}=35 \mu \mathrm{F}$ to $\mathrm{t}=0.4 \mathrm{~s}$ for $\mathrm{C}=55 \mu \mathrm{F}$.

These results clearly demonstrate that the performance of the machine is clearly influenced by the values of the selfpriming capacities. The choice made on $\mathrm{C}=40 \mu \mathrm{F}$ is not fortuitous but is in direct relation with the nameplate of the DSIG, in particular the current that must be supplied at a certain speed of rotation.

Table 1. Self-priming capacitor influency

\begin{tabular}{ccccccc}
\hline $\boldsymbol{C}[\boldsymbol{\mu} \boldsymbol{F}]$ & $\operatorname{tr}[\mathbf{s}]$ & $\mathbf{L m}[\mathbf{H}]$ & $\operatorname{im}[\mathbf{A}]$ & $\mathbf{v s}_{\mathbf{s}}[\mathbf{V}]$ & is [A] & ir [A] \\
\hline 35 & 2.0 & 0.1260 & 04.63 & 171.5 & 1.89 & 0.099 \\
40 & 1.0 & 0.1087 & 07.00 & 228.0 & 2.86 & 0.142 \\
45 & 0.6 & 0.0950 & 08.67 & 250.5 & 3.54 & 0.186 \\
50 & 0.5 & 0.0845 & 10.05 & 262.5 & 4.10 & 0.32 \\
55 & 0.4 & 0.0754 & 11.29 & 268.0 & 4.61 & 0.42 \\
\hline
\end{tabular}

\subsubsection{Influence of the resistance value}

In order to establish the influence of the values of the load resistance on the characteristics of the machine, we carried out simulations with resistances from $150 \Omega$ to $300 \Omega$ with a step of 50 .

Figure 23 shows that as the value of $\mathrm{R}$ increases, the magnetizing current im increases from 3.10 A for $\mathrm{R}=150 \Omega$ to $5.78 \mathrm{~A}$ for $\mathrm{R}=300 \Omega$. 


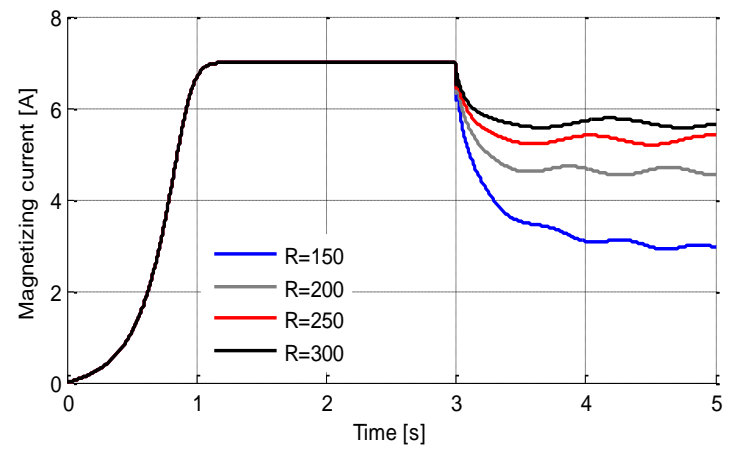

Figure 23. Influence of the resistance on the magnetizing current

Table 2. Load resistance influency

\begin{tabular}{cccccc}
\hline $\mathbf{R}[\mathbf{\Omega}]$ & $\mathbf{L m}[\mathbf{H}]$ & $\mathbf{i m}[\mathbf{A}]$ & $\mathbf{v}_{\mathbf{i}}[\mathbf{V}]$ & $\mathbf{i}_{\mathbf{i}}[\mathbf{A}]$ & $\operatorname{ir}[\mathbf{A}]$ \\
\hline 150 & 0.1350 & 3.10 & 112.00 & 1.54 & 1.78 \\
160 & 0.1334 & 3.44 & 129.00 & 1.77 & 1.96 \\
170 & 0.1312 & 3.84 & 142.00 & 1.92 & 2.00 \\
200 & 0.1270 & 4.71 & 167.50 & 2.22 & 2.02 \\
210 & 0.1254 & 4.81 & 172.00 & 2.27 & 2.00 \\
220 & 0.1243 & 4.96 & 177.00 & 2.32 & 1.95 \\
250 & 0.1225 & 5.40 & 187.60 & 2.42 & 1.84 \\
300 & 0.1198 & 5.78 & 194.80 & 2.48 & 1.65 \\
\hline
\end{tabular}

Table 2 summarizes the various parameters governing the operation of the DSIG under resistive load with the various resistance values. Thus, the voltage supplied and the current supplied increase with the increase in the value of the resistance. On the other hand, the rotor current reaches maximum values for a resistance range varying between 170 $\Omega$ and $210 \Omega$.

These results demonstrate that the performance of the machine is clearly influenced by the values of the load resistance.

\subsubsection{Velocity influency}

In order to establish the influence of the variation of the drive speed on the characteristics of the generator, a simulation with speeds close to that of synchronism with a step of 5.5 $\mathrm{rad} / \mathrm{s}$ are carried out.

Figure 24 shows that if the driving speed is increased, the magnetizing current increases from $4.62 \mathrm{~A}$ for a speed of 314.5 $\mathrm{rad} / \mathrm{s}$ to a value of $5.92 \mathrm{~A}$ for a speed of $325.5 \mathrm{rad} / \mathrm{s}$.

Figure 25 summarizes the evolution of magnetizing inductance which, unlike magnetizing current, decreases as speed increases. Figure 26 shows the evolution of the rotor current which increases with increasing speed. The same behavior is observed for the voltages supplied and the currents supplied.

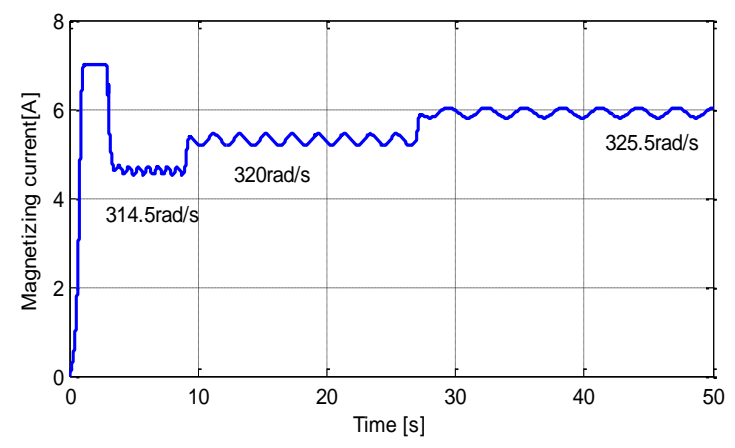

Figure 24. Speed influency on the magnetization current

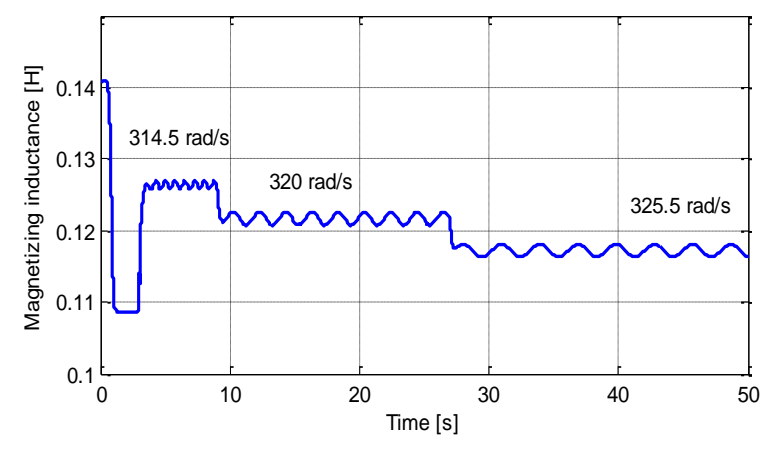

Figure 25. Speed influency on the magnetizing inductance

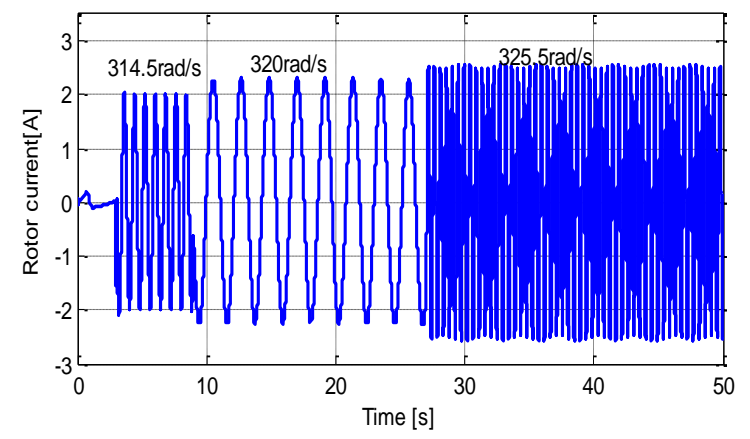

Figure 26. Speed influency on the rotor current

Table 3. Velocity influency

\begin{tabular}{ccccccc}
\hline $\mathbf{N}[\mathbf{r d} / \mathbf{s}]$ & $\mathbf{L}_{\mathbf{m}}[\mathbf{H}]$ & $\mathbf{i m}[\mathbf{A}]$ & $\mathbf{v}_{\mathbf{s}}[\mathbf{V}]$ & $\mathbf{i s}_{\mathbf{s}}[\mathbf{A}]$ & ir [A] & $\mathbf{f}[\mathbf{H z}]$ \\
\hline 314.5 & 0.1270 & 4.71 & 168 & 2.21 & 2.02 & 50.05 \\
320.0 & 0.1226 & 5.44 & 190 & 2.55 & 2.30 & 50.93 \\
325.5 & 0.1181 & 6.04 & 208 & 2.83 & 2.56 & 51.81 \\
\hline
\end{tabular}

Table 3 summarizes the operation of this machine when varying the drive speed. These results demonstrate that the performance of the DSIG is clearly influenced by the values of the drive speed.

\section{CONCLUSION}

Designing and building a pumping station is a complex task, which must take into account the constraints resulting from hydraulics, the pricing of the supply of electrical energy, while ensuring a good balance between investment and the cost of operation.

The choice of pump should be based on the analysis of demand and its daily and seasonal fluctuations and the possibility of expansion in the future.

Fluctuations in the supply of electrical energy can vary considerably, depending on the period of consumption, it is necessary to store water in tanks to maintain the distribution.

Solar pumping is an interesting technology for a maximum flow of $100 \mathrm{~m}^{3} / \mathrm{d}$ at TDH $=10 \mathrm{~m}$. Beyond that, the surface area of the solar panels to be installed quickly becomes large and the installation very expensive.

To meet the energy needs in isolated areas, the wind is one of the ideal energy vectors to replace fossil fuels in the long term and the introduction of photovoltaic energy becomes a necessity and the use of hybrid system becomes a necessity absolute to achieve filling the gaps of each renewable source of the hybrid system. 
The results obtained clearly indicate that the combination of these two sources in this region allows us to meet the drinking water needs of the locality, either during the day when the sunshine provides sufficient energy for pumping or at nightfall when the wind is blowing enough to obtain desired flows. Notwithstanding the use of dual star induction machines, as a generator or as a motor, which ensure operation in degraded mode in the event of phase losses.

\section{REFERENCE}

[1] Lalouni, S., Rekioua, D. (2009). Modeling and simulation of a photovoltaic system using fuzzy logic controller. 2009 Second International Conference on Developments in eSystems Engineering, Abu Dhabi, pp. 23-28. https://doi.org/10.1109/DeSE.2009.17

[2] Semache, A., Hamidat, A., Benchatti, A. (2015). Impact study of the solar energy on the energy performances of the rural housing in Algeria. International Journal of Heat and Technology, 33(4): 229-236. http://dx.doi.org/10.18280/ijht.330431

[3] Mayssa, F., Sbita, L. (2012). Advanced ANFIS-MPPT control algorithm for sunshine photovoltaic pumping systems. 2012 First International Conference on Renewable Energies and Vehicular Technology, Hammamet, pp. 167-172 https://doi.org/10.1109/REVET.2012.6195265

[4] Khan, T., Sarkar, S., Hossain, S., Ahmed, A., Pathik, B.B. (2013). The feasibility study of solar irrigation: Economical comparison between diesel and photovoltaic water pumping systems for different crops. 2013 International Conference on Electrical Information and Communication Technology (EICT), Khulna, pp. 1-5. https://doi.org/10.1109/EICT.2014.6777844

[5] Hajdidj, M.S., Bibi-Triki, N., Didi, F. (2017). Study and optimization of a renewable system of small power generation. European Journal of Electrical Engineering, 19(3-4): 133-154. https://doi.org/10.3166/EJEE.19.133154

[6] Adjati, A., Rekioua, T., Rekioua, D. (2020). Degraded mode of dual stator induction motor in pumping. Journal Européen des Systèmes Automatisés, 53(2): 273-282. http://doi.org/10.18280/jesa.530215

[7] Savay, L. (2006). Force hydraulique et machines à eau dans l'Antiquité Romaine. Colloque international Pont du Gard, pp. 139-140.

[8] Hadiouche, D., Razik, H., Rezzoug, A. (2000). Study and simulation of space vector PWM control of double-stator induction motor. 2000 IEEE- CIEP, Acapulco, Mexico, pp. 42-47. http://doi.org/10.1109/CIEP.2000.891389

[9] Kalantari, A., Mirsalim, M., Rastegar, H. (2002). Adjustable peed drive based on fuzzy logic for a dual Three- Phase Induction machine. Amir kabir University of Technology, Tehran- Iran, Proceedings in Electrimacs, Electric Drives II, 18-21 August 2002.

[10] Hadiouche, D. (2001). Contribution à l'étude de la machine asynchrone double étoile: modélisation, alimentation et structure. Thèse de Doctorat de l'Université Henri Poincaré de Nancy I, faculté des sciences et technique.

[11] Rekioua, D., Matagne, E. (2012). Optimization of Photovoltaic Power Systems: Modelization, Simulation and Control. Green Energy and Technology, Springer-
Verlag London. https://doi.org/10.1007/978-1-44712403-0

[12] Radziemska, E. (2005). Dark I-U-T measurements of single crystalline silicon solar cells. Energy Conversion and Management, 46(9-10): 1485-1494. https://doi.org/10.1016/j.enconman.2004.08.004

[13] Xiao, W., Dunford, W.G., Capel, A. (2004). A novel modeling method for photovoltaic cells. 2004 IEEE 35th Annual Power Electronics Specialists Conference (IEEE Cat. No.04CH37551), Aachen, Germany, 3: 1950-1956. https://doi.org/10.1109/PESC.2004.1355416

[14] Lee, B., Ehsani, M. (2003). Advanced simulation model for brushless dc motor drives. Electric Power Components and Systems, 31(9): 841-868. https://doi.org/10.1080/15325000390227191

[15] Gérgaud, O. (2002). Modélisation énergétique et optimisation économique d'un système de production éolien et photovoltaïque couplé au réseau et associé à un accumulateur. Thèse de doctorat, école normale supérieure de Cachan.

[16] Guettaf, A. (2011). Direct field oriented control of induction motor fed by wind turbine generator under saturation effect. Mediterranean Journal of Measurement and Control, 7(1): 190-196.

[17] Singh, B., Verma, M.V., Tandon, A.K. (2006). Rating reduction of static compensator for voltage control of three-phase self-excited induction generator. 2006 IEEE International Symposium on Industrial Electronics, Montreal, Que., pp. 1194-1199. https://doi.org/10.1109/ISIE.2006.295807

[18] Singh, G.K., Yadav, K.B., Saini, R.P. (2005). Modeling and analysis of multi-phase (six phase) self-excited induction generator. IEEE proceedings, The Eighth International Conference on Electrical Machines and Systems ICEMS, China, pp. 1922-1927. https://doi.org/10.1109/ICEMS.2005.202896

[19] Ahmed, T., Nishida, K., Nakaoka, M., Lee, H.W. (2004). Self-excited induction generator with simple voltage regulation scheme for wind turbine. The 30th Annual Conference IEEE Industrial Electronics Society, Bussan, Korea, pp. 86-91. https://doi.org/10.1109/IECON.2004.1433289

[20] Kishore, A., Prassad, R.C., Karan, B.M. (2006). Matlab simulink based dq modelling dynamic characteristics of three phase self-excited induction generator. Progress in electromagnetics research symposium, Cambridge, USA, 2(3): 312-316. https://doi.org/10.2529/PIERS050905011004

[21] Merabet, E., Abdessemed, R., Amimeur, H., Hamoudi, F., Abdelhamid, L. (2007). Influence de la charge sur une génératrice asynchrone double étoile (GASDE). International Conference on Renewable Energy ICRE'07, University of Bejaia, pp. 63-68.

[22] Poitiers, F. (2003). Etude et commande de génératrices asynchrones pour l'utilisation de l'énergie éolienne. Thèse de Doctorat, Université de Nantes, France.

\section{NOMENCLATURE}

$\begin{array}{ll}\text { AC/DC } & \text { Converter } \\ \text { DC/AC } & \text { Inverter } \\ \text { DC/DC } & \text { Converter } \\ \text { DSIG } & \text { Dual stator induction generator }\end{array}$




\begin{tabular}{|c|c|}
\hline DSIM & Dual stator induction motor \\
\hline GPV & Photovoltaic generator \\
\hline HPS & Hybrid pumping system \\
\hline PV & Photovoltaic \\
\hline $\mathrm{C}$ & Self priming capacitor \\
\hline $\mathrm{Cp}$ & Power exchange coefficient \\
\hline $\mathrm{C} 1, \mathrm{C} 2$ & Constants \\
\hline d & Inside diameter of the conduit \\
\hline Ec & Daily energy \\
\hline$f_{\text {rotor }}$ & Rotor frequency \\
\hline $\mathrm{Fr}$ & Coefficient of friction \\
\hline Gs & Sunshine \\
\hline Gsref & Sunshine referency \\
\hline I & Moment of inertia \\
\hline Icc & Short-circuit current \\
\hline Id \& iq & Direct \& quadratic current \\
\hline im & Magnetization current \\
\hline $\operatorname{Im}$ & Current at maximum power \\
\hline Imref & Referency current at maximum power \\
\hline ir,abc & Rotor current \\
\hline $\mathrm{i} 1, \mathrm{abc} / \mathrm{i} 2, \mathrm{abc}$ & Currents of star 1 and star 2 \\
\hline $\mathrm{K}$ & Multiplying coefficient \\
\hline $\mathrm{Kr}$ & Proportionality coefficient \\
\hline $\mathrm{Lm}$ & Magnetizing inductance \\
\hline $\mathrm{Lr}$ & Rotor inductance \\
\hline Ls & Stator inductance \\
\hline Lx,y & Mutual inductance \\
\hline $\mathrm{N}$ & Pump rotation speed \\
\hline $\mathrm{p}$ & Number of pole pairs \\
\hline Pdelivred & Electrical power \\
\hline Peol & Aerodynamic (turbine) power \\
\hline Pmec & Mechanical power \\
\hline$P_{\text {panel }}$ & Normalized power \\
\hline Q & Flow \\
\hline $\mathrm{R}$ & Blade length \\
\hline$r_{r}$ & DSIG rotor resistor \\
\hline$r_{s}$ & DSIG stator resistor \\
\hline $\mathrm{Rr}$ & DSIM rotor resistor \\
\hline Rs & DSIM stator resistor \\
\hline $\mathrm{T}$ & Temperature \\
\hline $\mathrm{TDH}$ & Total dynamic head \\
\hline Tem & Electromagnetic torque \\
\hline $\mathrm{Tj}$ & Cell junction temperature \\
\hline Tjref & Refrency cell junction temperature \\
\hline $\mathrm{T}_{\text {pumping }}$ & Pumping time \\
\hline $\operatorname{Tr}$ & Resistant torque \\
\hline
\end{tabular}

$\begin{array}{ll}\mathrm{Ts} & \text { Static torque } \\ \mathrm{T}_{\text {rotor }} & \text { Rotor period } \\ \mathrm{T}_{\mathrm{T}} & \text { Turbine torque } \\ \mathrm{V} & \text { Wind velocity } \\ \mathrm{Vt} & \text { Thermal voltage } \\ \mathrm{Vdr}, \mathrm{Vqr} & \text { Direct \& quadratic voltage } \\ \mathrm{V}_{\text {flow }} & \text { Flow velocity } \\ \mathrm{Vm} & \text { Maximum power voltage } \\ \mathrm{Voc} & \text { Open circuit voltage } \\ \mathrm{v} 1, \mathrm{abc} & \text { Stator voltage of star 1 } \\ \mathrm{v} 2, \mathrm{abc} & \text { Stator voltage of star } 2\end{array}$

\section{Greek symbols}

$\begin{array}{ll}\alpha, \beta & \text { Constant parameters } \\ \Delta \mathrm{Im} & \text { Temperature coefficient of current } \\ \Delta \mathrm{Vm} & \text { Temperature coefficient of voltage } \\ \theta \mathrm{e}, \theta \mathrm{m} & \text { Electric \& mechanical angle } \\ \eta_{\text {engine }} & \text { Engine efficiency } \\ \eta_{\text {inverter }} & \text { Inverter efficiency } \\ \eta_{\text {multi }} & \text { Multiplier efficiency } \\ \eta_{\text {pump }} & \text { Pump efficiency } \\ \lambda & \text { Specific speed } \\ \rho & \text { Air density } \\ \varphi \mathrm{d}, \varphi \mathrm{q} & \text { Direct \& quadratic fluxes } \\ \varphi \mathrm{r}, \mathrm{abc}, \varphi \mathrm{r} & \text { Rotor fluxes } \\ \varphi 1, \mathrm{abc}, \varphi \mathrm{s} 1 & \text { Stator fluxes of star 1 } \\ \varphi 2, \mathrm{abc}, \varphi \mathrm{s} 2 & \text { Stator fluxes of star } 2 \\ \omega \mathrm{mag} & \text { Magnetic energy } \\ \omega \mathrm{r} & \text { Rotation speed } \\ \omega \mathrm{rotor} & \text { Rotor pulsation } \\ \omega \mathrm{s} & \text { Stator pulsation } \\ \Omega & \text { Angular speed } \\ \Omega_{\mathrm{T}} & \text { Turbine angular speed }\end{array}$

\section{APPENDIX}

$\underline{\text { Photovoltaic panels SIEMENS SM 110-24 }}$

\begin{tabular}{cc}
\hline Designation & Value \\
\hline Panel maximal power. & POP $=110 \mathrm{~W}$ \\
Current at the maximum power point. & IOP $=3.15 \mathrm{~A}$ \\
Voltage at the maximum power point. & VOP $=35 \mathrm{~V}$ \\
Current of short circuit & ICC $=3.45 \mathrm{~A}$ \\
Open circuit voltage & VCO $=43.5 \mathrm{~V}$ \\
\hline
\end{tabular}

